\section{Humidifiers: the use of biocides and lung disease}

\author{
C A C Pickering
}

Over the last two decades several publications have reported outbreaks of interstitial lung disease caused by inhalational exposure to a chemical, usually at work, but occasionally in a domestic situation. These outbreaks frequently follow a change in formulation, which may be minor, ${ }^{1}$ of a chemical already being used in the workplace, or a change in process leading to its aerosolisation.

In 2006, paediatricians in South Korea became aware of a severe, rapid-onset interstitial pneumonitis in young children and infants; the disease responded very poorly to treatment, and mortality rates were close to $50 \% .^{2}$ Its seasonal presentation, with most cases presenting in the spring, raised the possibility of an infective aetiology; hypersensitivity pneumonitis was also considered. The failure to find any microbiological evidence for the former, and the distinct clinical and pathological features that distinguished it from the latter led to the consideration of other hypotheses. As a result, the Korean Centre for Disease Control set up a series of casecontrol studies designed to examine a wide variety of alternative environmental explanations. In early 2013, the findings of a small $(n=16)$ study of affected children were published ${ }^{3}$; intriguingly, they indicated that all the cases, but just a third of the matched controls, had exposure to disinfectant used in domestic humidifiers, producing an OR of 2.73 .

The epidemic in adults from the same country is described ${ }^{4}$ alongside the corresponding epidemiological investigation. ${ }^{5}$ As with the children, there was a very strong seasonal pattern to disease incidence and a clear clustering within families with an apparent predilection for pregnant or recently delivered women; 11 of the 15 female admissions were either pregnant or in the postpartum period. The tissue response was one of progressive, nongranulomatous, inflammation and, again, the disease appeared to have a rapid onset, was resistant to treatment and had a high mortality with five deaths; four patients survived following transplantation, and just

Correspondence to Professor C A C Pickering, North West Lung Research Centre, Wythenshawe Hospital, Manchester M23 9LT, UK; tony.pickering@manchester. ac.uk, cacgp@btinternet.com two following conventional treatment. The epidemiological study ${ }^{5}$ established to examine a range of indoor environmental factors, recruited 18 cases carefully matched to 121 hospital controls. The results again identified humidifier detergent as the likely cause of the outbreak, but in this case with an extraordinarily high, adjusted OR of 53.01 (95\% CI 6.33 to 444.17 ); it is not clear whether the apparent susceptibility of young women was related to the state of pregnancy or, perhaps more likely, to an increased exposure to biocide in the home. As a consequence of these findings, biocide detergents were withdrawn from the market in 2011; subsequently, there have been no further new cases reported.

South Korean winters and spring tend to be cold and dry with an average relative humidity of $60-65 \%$. The use of home humidifiers is common there, particularly to relieve respiratory symptoms and dry skin. In a questionnaire survey of pregnant women in three areas of the country, $45 \%$ reported using humidifiers in December or January, in most cases for long periods of the day. ${ }^{6}$ The first biocide for domestic humidifiers was introduced in South Korea in 1994, CMIT/MIT (chloromethylisothia$\mathrm{zol} / \mathrm{methylisothiazol}$ ), and was followed in 2000 by PHMG-phosphate (polyhexamethylene guanidine phosphate), most commonly used by the patients described here, and in 2009 by PGH (oligoethoxyethyl guanidine chloride). The timing of the introduction of PHMG is consistent with the development of this epidemic. Subsequent animal experiments have revealed inflammatory changes, similar to those seen in human cases, in PHMGexposed and PGH-exposed animals, but not in controls or those exposed to the CMIT/MIT. The guanides are good general-purpose bacteriocides, fungicides and algeocides having a high surface activity which disrupts the cell wall and cytoplasm of a wide range of micro-organisms; their major use is controlling microbiological growth in cooling systems.

The clinical picture described in these papers is unique. The exposure is to a 'nonirritant' chemical delivered in a particulate size capable of penetrating to bronchiolar and alveolar level in the lungs. The domestic humidifiers mainly used by the patients in these papers were warm mist, ultrasonic, and warm mist and ultrasonic; a study from the Korean Center for Disease Control and Prevention ${ }^{7}$ reported that when humidifier disinfectants are added to distilled water and used in an ultrasonic nebuliser, nanoparticles of 30-80 $\mathrm{nm}$ are generated, consisting of PHMG and PGH.

Humidification systems are used mainly in occupational settings where a stable relative humidity is required. They are used widely in a variety of industries including textiles, printing, timber, tobacco, cold stores, data centres, offices and automobile production. In the past, methods of cold water humidification included spraying water into incoming air, dripping water through a fibre mesh through which incoming air is forced, a spinning disc method in which a stream of water is trained against a rotating blade which atomises and blows it out of the humidifier, or the ultrasonic nebulisation of water into incoming air. The three former methods have largely now been discontinued, microbiological growth in static water proving difficult to control even with the use of a biocide. ${ }^{8}$ Microbial growth in workplace humidification systems has been reported to have caused cases of occupational asthma ${ }^{9}$ extrinsic allergic alveolitis ${ }^{10}$ and humidifier fever. ${ }^{11}$

The water supply to an ultrasonic nebuliser used in the workplace is directly from the mains, avoiding the presence of static water and, thus, the necessity of biocides. In the domestic setting, an ultrasonic nebuliser will have had a water supply coming from a small tank which, if not cleaned regularly, will develop microbial growth. In this outbreak, nebulisers were run with biocide in the water rather than it being used to clean the tank, a practise that was long ago deemed likely to be hazardous. ${ }^{12}$ Bronchial asthma ${ }^{13}$ as well as extrinsic allergic alveolitis ${ }^{14}$ have been described as a result of microbiological contamination of home humidifiers. In Western Europe, the use of home humidifiers is rare; rather, with the introduction of 'tight' buildings, the chief problem is in preventing high levels of humidity occurring in the home.

It is clearly necessary to keep home humidifiers clean, but running them with biocide detergents in the water is contraindicated. The tragedy of the Korean epidemic is a reminder of the importance of a full evaluation of the toxicity of chemical inhalants in the home. In this instance, the intended use of the biocides involved only dermal contact and possible ingestion and, therefore, was exempt from the submission of inhalation toxicology 
data. The use of these chemicals was then extended to humidifiers without recognition that this change in exposure route might cause significant health effects.

Competing interests None.

Provenance and peer review Not commissioned; internally peer reviewed.

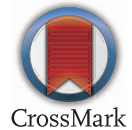

To cite Pickering CAC. Thorax 2014;69:692-693.

Published Online First 4 June 2014

\section{SLinked}

http://dx.doi.org/10.1136/thoraxjn-2013-204132

- http://dx.doi.org/10.1136/thoraxjnl-2013-204135

Thorax 2014;69:692-693.

doi:10.1136/thoraxjnl-2014-205739

\section{REFERENCES}

1 Moya C, Anto JM, Newman Taylor AJ; and the Collaborative Group for the Study of Toxicity in Textile Aerographic Factories. Outbreak of organising pneumonia in textile printing sprayers. Lancet 1994;344:498-502.

2 Cho YA, Kim SA, Jang SJ, et al. Toxic inhalational injury-associated interstitial lung disease in children. J Korean Med Sci 2013;28:915-23.

3 Yang HJ, Kim HJ, Yu J, et al. Inhalation toxicity of humidifier disinfectants as a risk factor of children's interstitial lung disease in Korea: a case-control study. PLoS One 2013;8:e64430.

4 Hong S-B, Kim HJ, Huh JW, et al. A cluster of lung injury associated with home humidifier use: clinical, radiological and pathological description of a new syndrome. Thorax 2014;69:694-702.

5 Kim HJ, Lee M-S, Hong S-B, et al. A cluster of lung injury cases associated with home humidifier use: an epidemiological investigation. Thorax 2014;69:703-8.

6 Chang MH, Park H, Ha M, et al. Characteristics of Humidifier Use in Korean Pregnant Women: The Mothers and Children's Environmental Health (MOCEH) Study. Environ Health Toxicol 2012;27: e2012003.

7 Korea Center for Disease Control and Prevention Interim report of epidemiological investigation on lung injury with unknown cause in Korea. Public Health Wkly Rep 2011;4:831-2.
8 Pickering CAC, Moore WKS, Lacey J, et al. Investigation of a respiratory disease associated with an air conditioning system. Clin Allergy 1976;6:109-18

9 Burge PS, Finnegan MJ, Horsfield $N$, et al. Occupational asthma in a factory with a contaminated humidifier. Thorax 1985;40:248-54.

10 Bansazak EF, Thiede WH, Fink JN. Hypersensitivity pneumonitis due to contamination of an air conditioner. N Engl J Med 1970;283:271-76.

11 Pestalozzi C. Febrile gruppenerkrangungen in einer modellschreinerei durch inhalation von mit schimmelpilzen kontaminiertem befeuchterwasser. ('Befeuchterfieber'). Schweiz Med Wochenschr 1959:89:710-13.

12 Pickering CAC, Newman Taylor A. Extrinsic allergic bronchioloalveolitis (hypersensitivity pneumonitis). In: Parkes WR, ed. Occupational lung disorder. 3rd edn. Oxford: Butterworth Heinemann, 1994.

13 Solomon WR. Fungus aerosols arising from cold mist vaporizers. J Allergy Clin Immunol 1970;54:222-8.

14 Kane GC, Marx JJ, Prince DS. Hypersensitivity pneumonitis secondary to Klebsiella oxytoca. A new case of humidifier lung. Chest 1993; 104:627-29.

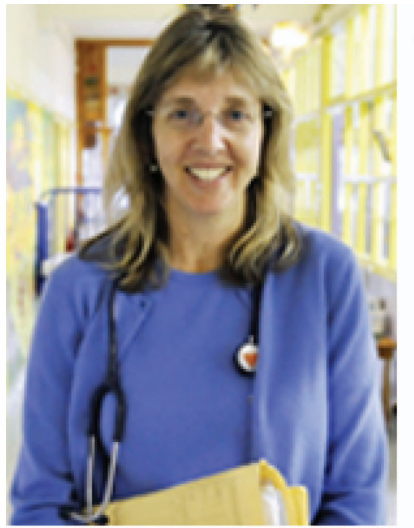

\section{ATS award}

Many congratulations to Thorax Associate Editor, Professor Heather Zar, who has been given the 2014 World Lung Health Award by the American Thoracic Society in recognition of work that has "the potential to eliminate gender, racial, ethnic, or economic health disparities worldwide". Heather is based at Red Cross Children's Hospital, Cape Town, South Africa, and her research encompasses many aspects of paediatric infectious diseases, including pneumonia, TB and HIVIAIDS, as well as asthma and now a new birth cohort study. A superb achievement! 